\title{
Incomplete Oblique Fissure, Absence of Horizontal Fissure: A Case Report
}

\author{
J.Sumalatha ${ }^{1}$, T. Sobha devi ${ }^{2}$ \\ ${ }^{1}$ Post graduate, Dept. of Anatomy, S.V. Medical college, Tirupati, A.P, NTRUHS \\ ${ }^{2}$ Assistant Professor, Dept. of Anatomy, S.V. Medical college, Tirupati, A.P, NTRUHS
}

\begin{abstract}
The right Lung classically has one oblique fissure and one horizontal fissure and Three Lobes namely Upper, Lower, and middle Lobes. Variations in the lung fissures and lobes have been described by many authors which have got their Surgical and Radiological importance. During Routine dissection in the Department of Anatomy, S.V. Medical College, Tirupati, we encountered an Incomplete oblique Fissure, Absence of Horizontal fissure in the Right Lung of an Adult male Cadaver. Anatomical Knowledge of the variations of Fissures of Lung are important for C.T. Surgeons performing Lobectomies, and Radiologists interpreting $X$-Rays.
\end{abstract}

Keywords: Right Lung, Oblique Fissure, Horizontal Fissure, Incomplete lobes

\section{Introduction}

Right lung is broader and heavier than the left lung. Two fissures oblique and horizontal, divide it into three lobes namely, upper, middle and lower. The oblique fissure separates the lower lobe from the remaining two lobes. It runs obliquely and crosses the inferior border of the lung about $7.5 \mathrm{~cm}$ behind its anterior end. The horizontal fissure separates the upper and middle lobe. It begins from the oblique fissure, runs horizontally and cuts the anterior border at inner end of fourth costal cartilage. The longer and lighter left lung is divided into a superior and an inferior lobe by an oblique fissure which extends from costal to medial surfaces of the lung both above and below the hilum ${ }^{3}$

The fissures facilitate the movement of the lobes in relation to one another, which accommodates greater distention and movement of the lobes during respiration. The fissures may be complete, incomplete or absent. In case of complete fissure the lung lobes are held together only at the hilum by the bronchi and the pulmonary vessels. Parenchymal fusion of varied extent along the floor is found in case of incomplete fissure ${ }^{4}$. Knowledge of the anatomy and variations of the major fissures are essential for recognizing their variable imaging appearances as well as related abnormalities. The cardiothoracic surgeons performing segmental lung resections and the radiologists must have a detailed knowledge of variations of classical and accessory fissures regarding their length, depth, positions etc to have uncomplicated peroperative and postoperative events and proper radiological interpretations respectively.

\section{Materials And Method}

Anomaly was observed during Routine dissection in the Department of Anatomy, S.V.Medical College, Tirupati in an Adult male cadaver. Both lungs were observed, Photographs were taken.

\section{Observations}

Right Lung showed an inomplete Oblique Fissure, Absence of Horizontal Fissure.Left Lung is normal. Incomplete oblique fissure started from the Apex of the Right Lung at about $12.5 \mathrm{cms}$ at the Level of MidAxillary line.It runs Antero inferiorly over the Sternocostal surface and cuts the Inferior border of lung at about $19 \mathrm{cms}$ from the Apex or $6.5 \mathrm{cms}$ from the anterior border.It runs Along the Inferior surface for $5.5 \mathrm{cms}$ and ends blindly at the junction of Mediatsinal and Inferior surfaceat about $4.5 \mathrm{cms}$ from the Anteroinferior aspect of Hilum.Depth of the fissure is about $2 \mathrm{cms}$ proximally, $2.5 \mathrm{cms}$ at the terminal part, $3.5 \mathrm{cms}$ in the deepest part.No other Accessory fissures note. right lung is incompletely divided into 2 lobes.Tertiary Bronchi are 10 in number. Relations of tertiary bronchi with pulmonary artery branches ,pulmonary vein tributaries are normal. Parenchymal fusion of oblique fissure is represented by an Hypopigmented Line . Horizontal Fissure is completely absent. Figures 1,2,3,4, showed the observations 

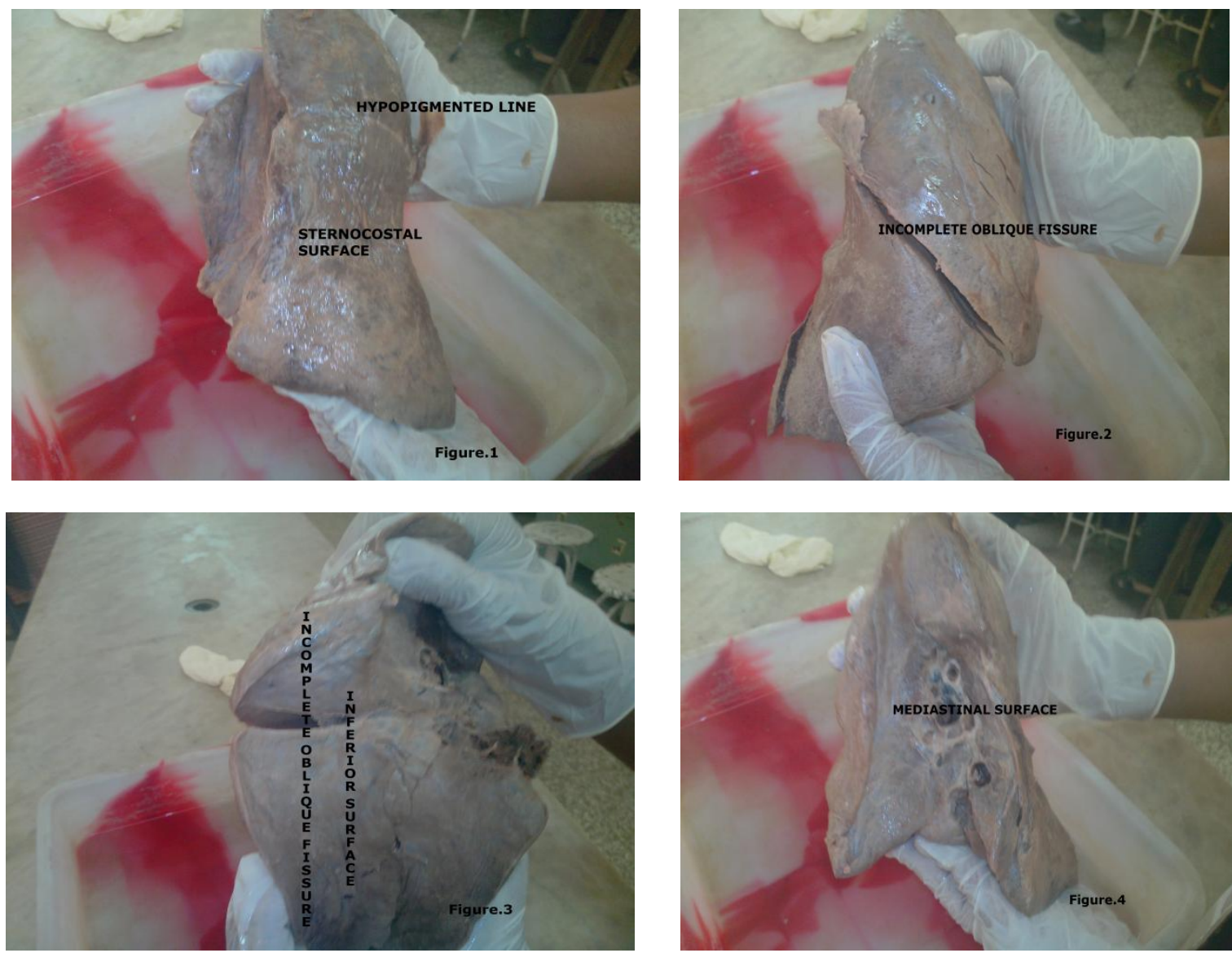

\section{Discussion}

The fissures facilitate the movement of the lobes in relation to one another, which accommodates greater distention and movement of the lobes during respiration. The fissures may be complete, incomplete or absent. In case of complete fissure the lung lobes are held together only at the hilum by the bronchi and the pulmonary vessels. Parenchymal fusion of varied extent along the floor is found in case of incomplete fissure. Finding accessory fissures in lung specimens is not uncommon, but appreciating them on radiographs and CT scans is difficult and hence they are either not appreciate as distinct entities or are completely misinterpreted. In addition to those fissures lung might also have accessory fissures, usually indicating junction between bronchopulmonary segments. As per Godwin ${ }^{3}$, they are superior accessory fissure, inferior accessory fissure or left minor fissure. No oblique fissure could be detected in $8 \%$ lungs of left and $11.54 \%$ of right side. Horizontal fissure was completely absent in $34.6 \%$. Various degree of parenchymal fusion was more common on the right side. None of the oblique fissures had uniform depth Sumita Dutta ${ }^{11}$ Fifty pairs of lungs were used for the study, Seven right lungs showed absence of horizontal fissure while one specimen showed absent oblique fissure,there is a wide range of difference in occurrence of major, minor and accessory fissures between and among different populations. Knowledge of such variations might explain bizarre presentation of certain clinical cases pertaining to lung pathologies Ajay Ratnakar rao Nene

Study was conducted on 48 lung specimens by Suja Mary Jacob ${ }^{5}$, among which 30 are right and 18 left lungs,In right lungs, the horizontal fissure was absent in 2lungs (6.6\%) and incomplete horizontal fissure was found in 25 lungs ( $83.4 \%)$. Oblique fissure was incomplete in 15 lungs(50\%). One lung showed absence of oblique fissure (3.4\%). An accessory fissure was observed in 4 lungs (13.3\%).On the basis of CT scans, Otsuji et al. $(1993)^{9}$ made a analysis of both lungs in 154 patients, including seven cadavers, and came to the conclusion that the frequency of the incomplete inter-lobar fissure was high in right sided lungs (83.1\%), when compared to the left lungs (50\%)

Craig and Walker $(1997)^{2}$ have proposed a fissural classification based on both the degree of completeness of the fissures and the location of the pulmonary artery at the base of the oblique fissure.Four stages have been described. Grade I - complete fissure with entirely separate lobes; Grade II - complete visceral cleft but parenchymal fusion at the base of the fissure; Grade III - visceral cleft evident for a part of the fissure; and Grade IV - complete fusion of lobes with no evident fissural line, Present case falls under Grade III 
S. Meenakshi et $\mathrm{al}^{10}$ studied on 30 pairs of lungs, Five right-sided lungs showed absence of horizontal fissure, 19 showed incomplete horizontal fissure. Eleven right-sided and 14 left-sided lungs showed incomplete oblique fissure and two right-sided lungs showed both absence of horizontal fissure and an incomplete oblique fissure. Accessory fissure was seen in three left-sided and one right-sided lungs

N. Bhimai Devi et al $^{8}$ studied on 22 cadavers and observed Two left lungs showed absence of fissures; in eight left lungs incomplete oblique fissure was observed. In four right lungs of transverse fissure was incomplete and in two right lungs incomplete oblique and transverse fissures were found. In two cadavers accessory lobes were present, one on right side and one on left side

M.A,Eroje et $\mathrm{al}^{7}$ found 2 cases both belongs to right lung, $1^{\text {st }}$ one has a horizontal and incomplete oblique fissure, $2^{\text {nd }}$ one has a complete oblique fissure with complete absence of horizontal fissurewhich differs with present case.

Incomplete development of the lung leads to incomplete formation of the fissures or causes their absence. In both the cases parenchymal fusion is seen. When part of the fissure is absent, it is always toward the mediastinal side of the fissure. Incomplete fissure may lead to the spread of disease and collateral air drift (Hayashi et al., 2001) ${ }^{4}$. It may alter the usual patterns of collapse seen in patients with endobronchial lesions and may also give rise to atypical type of pleural effusion (Meenakshi et al. ( $^{10}$. Familiarity with the appearance and implications of incomplete fissure is important for planning of lobar resection because there is a higher prevalence of air leak in lobar fusion (Hayashi et al. $)^{4}$.

\section{Summary And Conclusion}

Pneumonia in a particular lobe is contained within the confines of the lobe by complete fissures. In patients with incomplete fissures ,pneumonia may spread to adjacent lobes through the parenchymal continuation. Odd lobar involvement with carcinoma of the lung may be explained on a similar basis. A variety of genetic and environmental factors might affect development of these fissures. Knowledge of such variations might explain bizarre presentation of certain clinical cases pertaining to lung pathologies. Anatomical knowledge of fissures and lobes are important for CT surgeons, radiologists for interpreting x-rays, CT scans and MRI

\section{References}

[1]. Ajay Ratnakarrao Nene, Krishna Swami Gajendra, Manchiraju Venkata Ramananda SarmaLung lobes and fissures: a morphological Study October 24, 2011 doi:10.2399/ana.10.005 International journal of Experimental and Clinical Anatomy

[2]. CRAIG SR, WALKER WS (1997) A proposed anatomical classification of the pulmonary fissures. J R Coll Surg Edin, 42: 233234.

[3]. Godwin JD, Tarver RD.Accessory fissures of the lung. AJR Am J Roentgenol.1985;144:39-47.

[4]. Hayashi K,Aziz A,Ashizawa K,Hayashi H,Nagaoki K,Otsuji H.Radiographic and CT appearances of the major fissures.Radiographics.2001;21(4):861-874.

[5]. JACOB, S. M. \& PILLAY, M. Variations in the inter-lobar fissures of lungs obtained from cadavers of South Indian origin. Int. J. Morphol., 31(2):497-499, 2013.

[6]. Lydia S. Quadros, Ramesh Palanichamy and Antony S. D’souzaVariations in the lobes and fissures of lungs - a study in South Indian lung specimensEur. J. Anat. 18 (1): 16-20 (2014)

[7]. M,A,Eroje and F.M.Onyije; Lobar Variations of Right Lung as Seen in a Nigerian Cadever:A Case Report; Asian Journal of Biological Sciences 4 (2):196-200, 2011

[8]. N. Bhimai Devi *, B. Narasinga Rao**, V.Sunitha***Morphological variations of lung- A cadaveric study in north coastal Andhra PradeshInt J Biol Med Res. 2011; 2(4): 1149 - 1152

[9]. Otsuji, H.; Uchida, H.; Maeda, M.; Iwasaki, S.; Yoshiya, K.; Hatakeyama, M.; et al. Incomplete interlobar fissures: bronchova scular analysis with CT. Radiology, 187(2):541-6, 1993.

[10]. S. Meenakshi, K.Y. Manjunath and V. Balasubramanyam Morphological Variations of the Lung Fissures and Lobes, Indian J Chest Dis Allied Sci 2004; 46 : 179-182

[11]. Sumita Dutta1, Lopamudra Mandal1, Sanjay Kumar Mandal2, Jayanta Biswas3, Ansuman Ray1, ManimayBandopadhyay4 NATURAL FISSURES OF LUNG- ANATOMICAL BASIS OF SURGICAL TECHNIQUES AND IMAGING NATIONAL JOURNAL OF MEDICAL RESEARCH print ISSN: 22494995 | eISSN: 22778810 